\title{
Laboratorio de Ensayo de Resistencia al Fuego
}

\author{
JUAN DE DIOS RIVERA \\ Department of Mechanical and Metallurgical Engineering \\ Pontificia Universidad Católica de Chile \\ Vicuña Mackenna 4860-Macul \\ Santiago, Chile
}

PABLO MATAMALA

Laboratorio de Resistencia al Fuego, DICTUC

Pontificia Universidad Católica de Chile

Vicuña Mackenna 4860-Macul

Santiago, Chile

JOSE L. TORERO

School of Civil and Environmental Engineering

The University of Edinburgh

Edinburgh, EH9 3JN, U.K.

\begin{abstract}
Although fire statistics in Chile are not very complete, those available clearly show that fire losses have grown significantly in the last few years. Insurance reports indicate that fire related claims have grown almost three fold between 1989 and 1997 (from 6 to more than 17 million dollars [1]). This significant increase in losses can be attributed to many factors of which one of great importance is the dramatic change in construction practices in Chile. Among the changes are a significant increase in construction volume, industrial growth, development of local construction methods and technology and an increasing preference for taller and larger buildings. As an example it can be stated that 23 out of the 25 tallest buildings in Santiago were built within the last 10 years [2]. Despite this dramatic change, Chilean codes and standards have remained almost unaltered throughout the same period[3]. Furthermore, training and education in the area of fire safety is restricted to the fire service and a few occasional training courses. Fire safety authorities and practitioners generally fulfill their roles with simply an intuitive knowledge of current technology and practices. It is therefore clear that a dramatic influx of technology into fire safety practices is necessary in Chile.
\end{abstract}

It is within this framework that the "Laboratorio de Ensayo de Resistencia al Fuego" was developed at the Pontificia Universidad Catolica de Chile. The laboratory is a joint venture between the Department of Mechanical and Metallurgical Engineering and the Department of Construction Management and Engineering. The Chilean Government collaborated through the Fund for Development and Innovation (Fondo para el Desarrollo e Innovación (FDI-CORFO)). The University and the Ministry of Housing and Urbanism provided significant matching funds. The laboratory officially opened in May 2002.

The first stage of development has emphasized the construction of equipment that conforms to Chilean standards that require certification for fire resistance and material flammability. A single oven that allows for testing for fire resistance of horizontal and 
vertical samples was designed and built with local technology. It fulfils all requirements established by Chilean standards as well as ASTM-E-119, NFPA 251 and ISO 834. An innovative aspect of this oven is that it is capable of rotating, thus a single oven can perform the task of testing horizontal and vertical structural elements as well as the test of columns exposed on their four faces to the fire. The oven is fully instrumented for automatic control and data acquisition. Tests can be performed on horizontal samples of dimensions up to $4.5 \mathrm{~m}$ by $3.75 \mathrm{~m}$, vertical structural elements up to $3.4 \mathrm{~m}$ by $2.75 \mathrm{~m}$ and columns $2.7 \mathrm{~m}$ high. The same oven can be used, according to Chilean standards, for the testing of doors, glass assemblies and other fire containment elements. Different flammability tests have also been developed according to Chilean practices and include tests for general fire behavior of materials, wall linings and fabrics, as well as for selfsupporting and flexible plastics when exposed to a flame.

Although the main instrumentation developed is associated with current practices in standard testing, this infrastructure serves only as a point of departure. The expectation for this laboratory is to be a focal point for the development of new standards and technology. Fire safety problems related to the Chilean reality will be studied in conjunction with industry to develop better products, to set new regulatory requirements, and to perform scientific research. The market for fire research, development and testing within Chile is quite small and, therefore, it is necessary to converge within a single laboratory, testing services, development of new technology and scientific research.

Contact has been established with local manufacturers of building materials to help them design and produce better materials and constructive elements in terms of their fire behavior. Preliminary mathematical modeling of multi-layer walls has been performed to serve as a guide in the development of better building systems. Additionally, conversations are being held with intumescent painting manufacturers in terms of devising new standards for testing of these protective coatings. The desired methodology is to perform simple small-scale tests that will allow characterizing the coating. These tests will be complemented with modeling and validation via large-scale tests. Finally, this laboratory seeks to cooperate with industry directly by providing advice on appropriate safety practices.

Maybe the most important aspect of the mission of the laboratory is to provide training at all levels. The personnel associated to the laboratory is devoted to the development of seminars for practitioners as well as in-house training for industry and government officials. At the university level a series of three courses will be developed to provide general fire safety training for engineers, construction managers and architects. This series will comprise of an introductory course that will branch into subsequent fire dynamics and design of fire protection systems courses. It is expected that the first offering of the introductory course will be made in 2003.

\section{REFERENCES}

1. Boletín Estadístico, Incendio y sus adicionales, Asociación de Aseguradores de Chile A. G., 1987-1997

2. www.skycrperpage.com

3. Normas Chilenas, Instituto Nacional de Normalizacion, 1999.

KEYWORDS: Fire laboratory, testing, flammability, fire resistance 